\title{
A widely displaced Galeazzi-equivalent lesion with median nerve compromise
}

\author{
llias Galanopoulos, ${ }^{1}$ Quentin Fogg, ${ }^{2}$ Neil Ashwood, ${ }^{1}$ Katherine Fu ${ }^{3}$
}

${ }^{1}$ Department of Trauma and Orthopaedics, Queen's Hospital, Burton-on-Trent, UK

${ }^{2}$ Department of Laboratory of Human Anatomy, University of Glasgow, Glasgow, UK

${ }^{3}$ Department of Medicine, Imperial College Healthcare NHS Trust, London, UK

Correspondence to llias Galanopoulos, galanop.lias@gmail.com

\begin{abstract}
Summary
We present the case of a 14-year-old boy with a right distal radial fracture accompanied by a severely displaced complete distal ulnar physeal separation and associated median nerve compromise. This injury is known as Galeazzi-equivalent lesion in children and is an extremely rare injury associated with growth arrest. Recognition of the lesion can be difficult but wide displacement may be associated with other significant injuries such as neurovascular compromise. Prompt intervention reversed the neurological symptoms. At 10-month postoperation there was neither growth arrest nor loss of motion. Complete separation of the ulna physis remains often because of soft tissue interposition or capsule problems and prompt reduction is recommended in the literature as a priority.
\end{abstract}

\section{BACKGROUND}

Physeal fractures account for about $18 \%$ of all fractures in children and are usually classified according to the Salter-Harris classification system. The majority of these injuries are type II in Salter-Harris classification. About 3.3\% of all physeal injuries involve the distal ulna. In 11-50\% of the cases, distal radius fractures are accompanied with fractures of the ulna. ${ }^{1}$

Some Salter-Harris types I and II distal ulnar epiphysial injuries have been reported as needing open reduction ${ }^{2-5}$ because of either tendon interposition ${ }^{3}$ or a rupture in the capsule. ${ }^{4}$

The Galeazzi-fracture dislocation is a well-known injury including fracture of the distal radial shaft and dislocation of the distal radioulnar joint (DRUJ). It is rare in adults and even more uncommon in children. A variant of the classic injury, the Galeazzi-equivalent fracture, consists of a fracture at the distal radial metadiaphyseal area with complete distal ulnar epiphysial separation instead of the more common pattern of DRUJ dislocation. ${ }^{67}$

This is the first case noted to have neurological compromise within the literature requiring urgent treatment.

\section{CASE PRESENTATION}

A 14-year-old boy presented to the accident and emergency department after a fall on his right outstretched hand while playing handball. On examination the right wrist was swollen and deformed, with tenderness over the distal radius and ulna on palpation. The skin was intact and the elbow and proximal forearm were nontender. There was reduced sensation over the area of the median nerve distribution but with no distal vascular compromise.

\section{INVESTIGATIONS}

Antero-posterior and lateral radiographs of the right wrist showed a dorsally displaced and rotated Salter-Harris type
I fracture of the distal ulnar epiphysis with a dorsally displaced metaphysical fracture of the distal radius (figure 1). These findings suggested the so-called paediatric Galeazziequivalent fracture, which is very rare among this population.

\section{TREATMENT}

Closed reduction was achieved under general anaesthesia and Kirschner wires were used to stabilise the fracture fragments (figure 2). The first K-wire was inserted in the radius using the Kapandji technique and another K-wire was then inserted from the radial side to offer more stability. Finally, the ulnar physeal fracture was fixed with one fine K-wire which was passed across the growth plate. An above-elbow cast was applied and left in place for 6 weeks to allow the fractures and the soft tissue injuries to heal.

Urgent reduction was necessary because of median nerve involvement and in order to reduce the risk of growth disturbance. Internal fixation using smooth Kirschner wires was performed to maintain the mechanics of the distal radio-ulnar joint and to reduce the chances of growth arrest. The importance of the latter is related to the fact that $70-80 \%$ of the growth of the ulna is from the distal growth plate and epiphysial injuries have been reported to cause growth disturbance in more than $50 \%$ of cases. ${ }^{2}$

\section{OUTCOME AND FOLLOW-UP}

At follow-up 10 months postsurgery, the mean active range of motion nearly equals to the contralateral wrist in flexion/ extension, pronation/supination and ulnar/radial deviation. There was also equivalent grip and pinch strength compared to the contralateral side and no evidence of median nerve disturbance. Radiographic evaluation did not show any signs of growth arrest at 10 months (figure 3 ) but continued radiographic assessment until skeletal maturity to monitor 


\section{BMJ Case Reports}

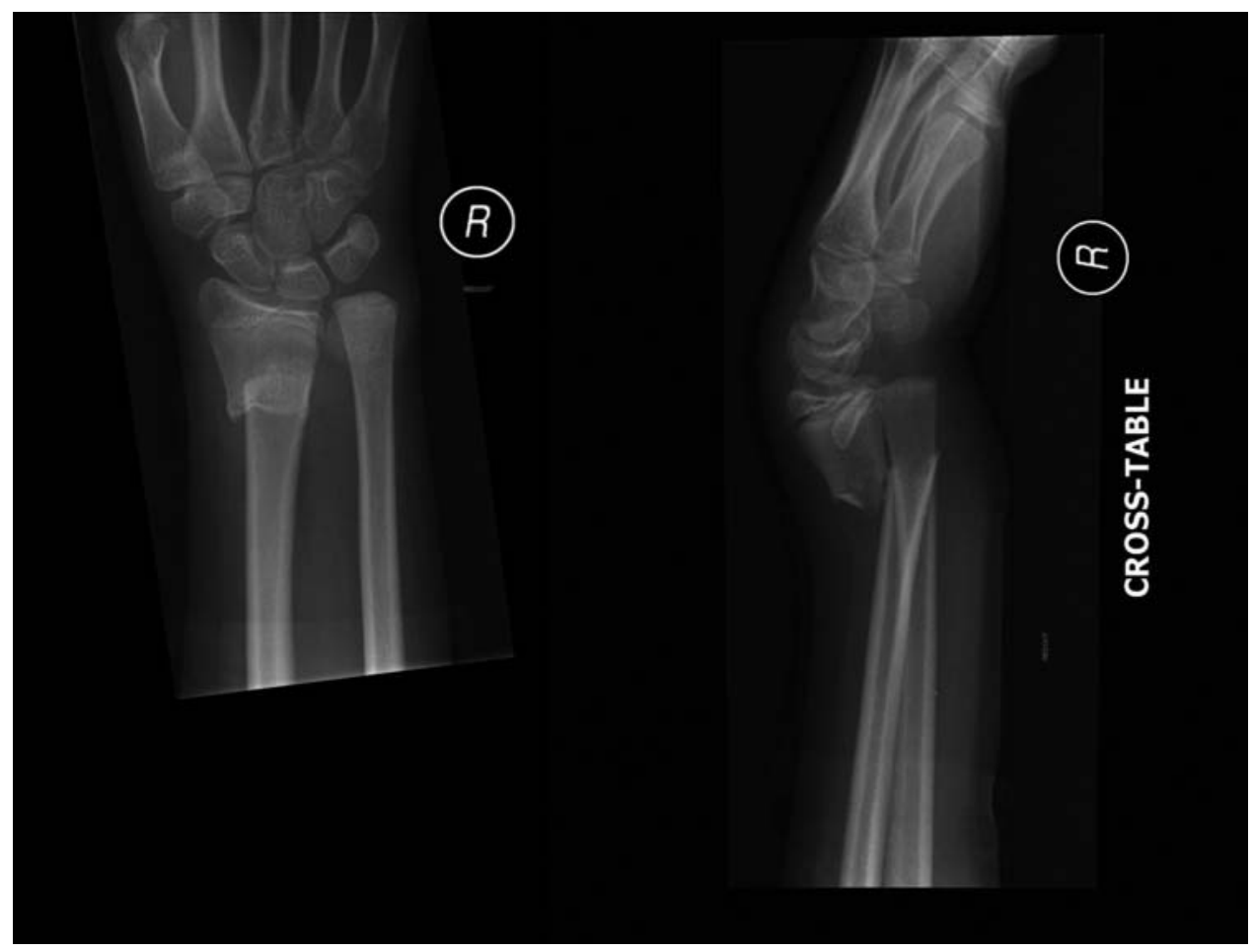

Figure 1 Initial radiographs showing a distal radial fracture with complete distal ulnar epiphysial separation with evidence of preservation of the distal radioulnar joint.

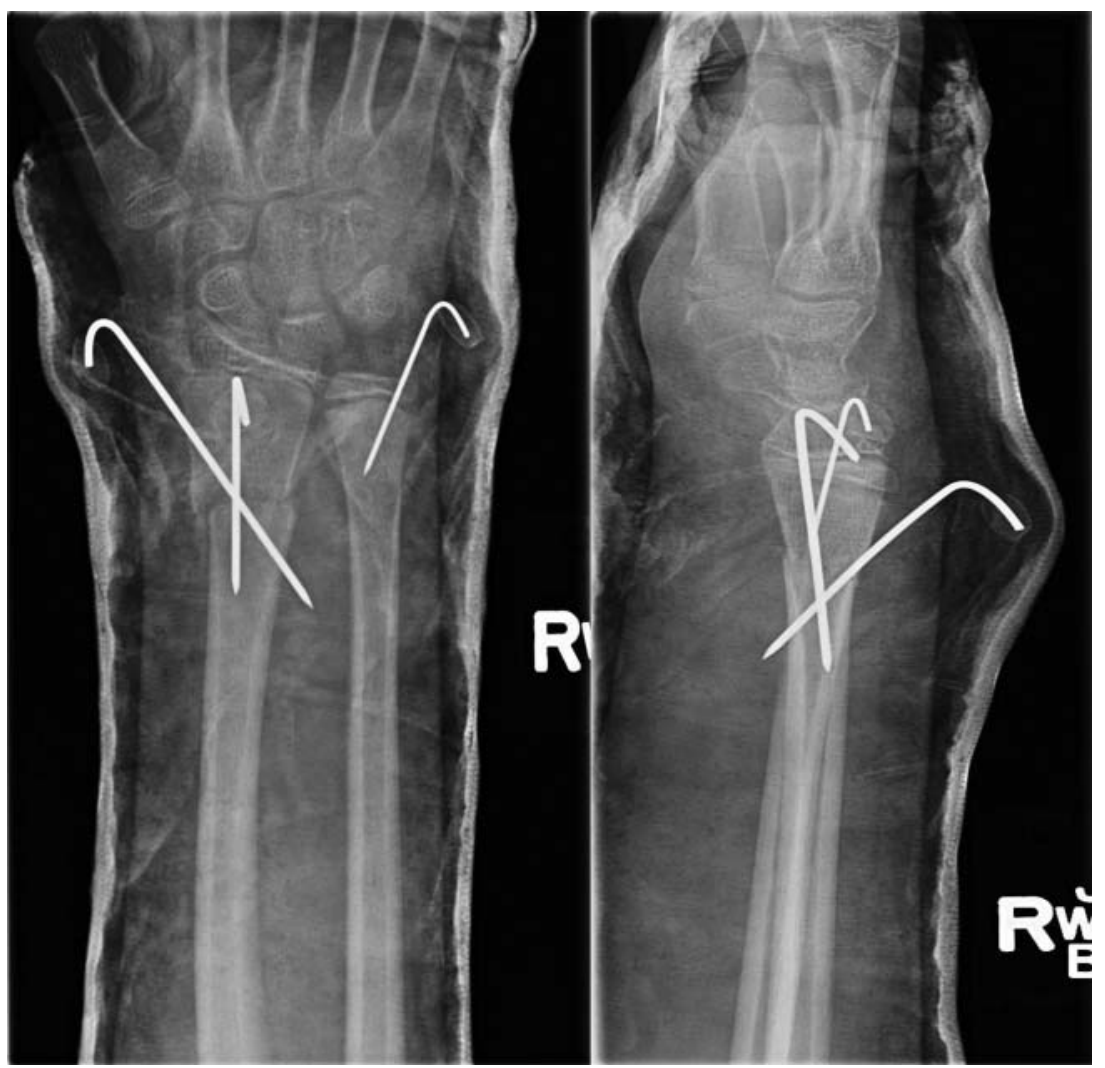

Figure 2 Postoperative radiographs with the arm immobilised in plaster. 


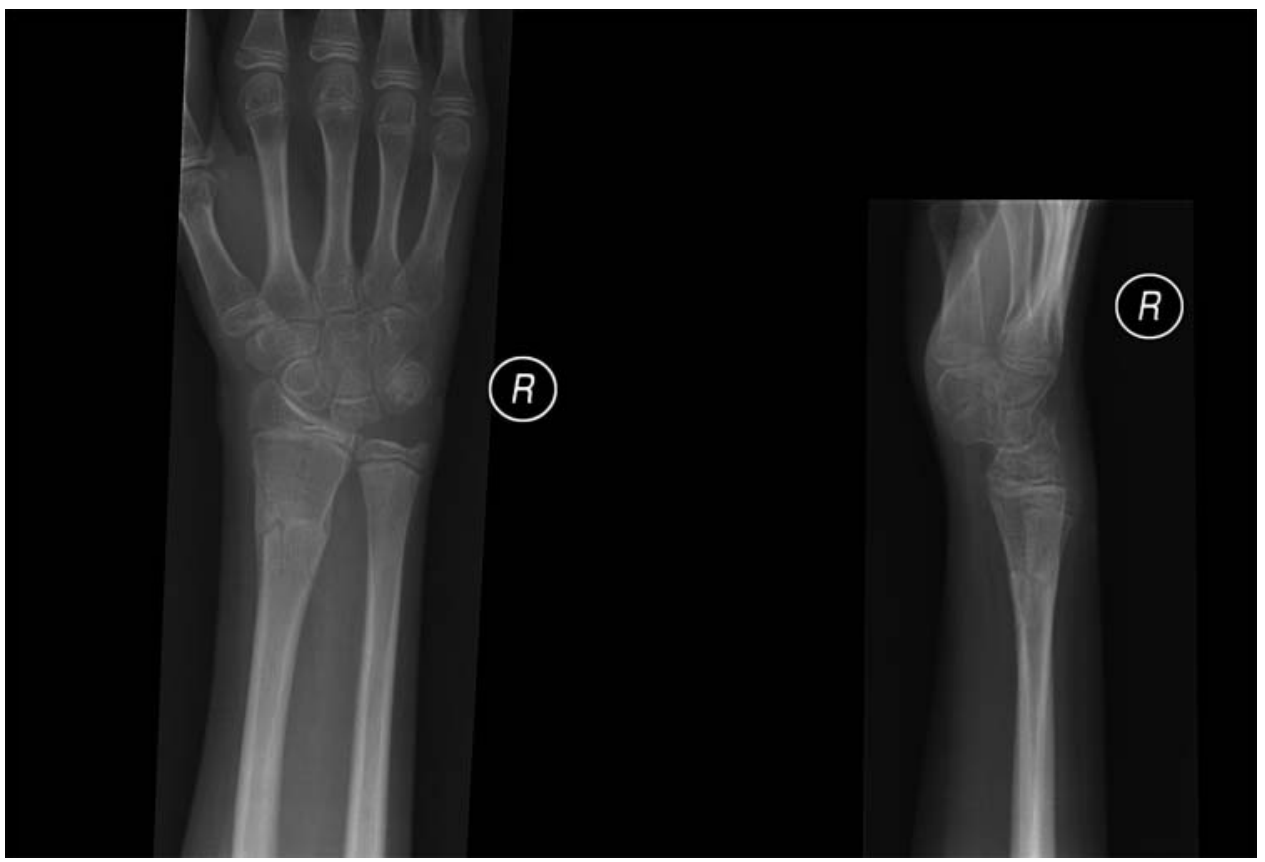

Figure 3 Radiographs after removal of K-wires show complete healing of fractures with excellent alignment in both anteroposterior and lateral views.

for possible growth disturbance of the distal ulnar physis has been advised to both parents and the injured individual.

\section{DISCUSSION}

The uncommon paediatric Galeazzi-equivalent injury usually involves an ulnar physeal fracture with distal radioulnar joint preservation rather than a soft tissue disruption through the distal radioulnar joint. Therefore, there is no rupture of the distal ligamentous stabilising system between the radius and ulna, which includes the triangular fibrocartilage complex, interosseous ligaments and the ulnar periosteal tube.

In this paper we presented a completely displaced Salter-Harris type I injury of the distal ulna epiphysis accompanied by a displaced distal radial metadiaphyseal fracture, thus a Galeazzi-equivalent type of injury, which is extremely rare. The level of displacement may have contributed to the soft tissue injury and nerve compromise. Previous case illustrations have not shown such a wide displacement. There was nothing unique about the mechanism of injury, although the described cases occur around adolescence when the growth plate is starting to fuse and the forces required to shear the ulna growth plate off may lead to severe tissue disruption, hence the higher rate of open reduction and risk of nerve compromise.

Clinicians should be aware of the risk to the vascular supply to the hand in such fractures although this is extremely rare. In such a case, symptoms can include, apart from numbness or paraesthesia, skin colour changes, temperature change to the limb, pain and absent pulses.

It is also important to carefully assess distal radial-ulnar paediatric injuries when they occur, as they can lead to poor long-term results if misdiagnosed or maltreated. These traumatic lesions are misdiagnosed in around 41\% of the cases. This can lead to growth plate problems and may result in instability, functional loss of range of motion, loss of strength and occasionally cosmetically poor outcomes. $^{8} 9$

Physeal growth arrest is frequent with distal ulnar physeal fractures occurring in $21-55 \%$. Cannata et al, ${ }^{10}$ showed in a large series of patients with distal ulnar physeal injuries treated with manipulation under anaesthesia and plaster, that growth disturbances occurred regardless of the classification type. However, all patients were fully asymptomatic at long-term follow-up, except for those who had forearm bone growth discrepancy of more than $1 \mathrm{~cm}$.

Despite anatomical reduction and stable fixation of the fracture, premature partial fusion of the distal ulnar physis might still occur especially in younger patients and so follow-up until skeletal maturity is advisable.

\section{Learning points}

- Emergent closed reduction and internal fixation are suggested as the treatment of choice for a displaced Salter-Harris type I fracture of the distal ulna to avoid nerve compromise in the short term. Even in the absence of nerve palsy, urgent treatment is of paramount importance, since delayed intervention is associated with higher risk of long-term growth compromise.

- Accurate reduction and delicate fixation with fine smooth K-wires are recommended to prevent growth disturbances and distal radio-ulnar joint malfunction in the long term. Occasionally, closed reduction cannot be achieved because of soft tissue interposition and in these cases an open reduction is required. ${ }^{9} 1112$ 


\section{BMJ Case Reports}

- It is always important to rule out the possibility of radial or ulnar artery compromise and distinguish it from a possible median nerve compression by means of clinical examination and Doppler ultrasound.

- In this case, we considered the Kapandji technique as a safe and effective method of K-wire fixation with all the advantages of a minimally invasive procedure, although it has not previously been described as a means of fixation in a paediatric Galeazzi-equivalent injury.

\section{Competing interests None.}

\section{Patient consent Obtained}

\section{REFERENCES}

1. Peterson HA. Epiphyseal growth plate fractures. Berlin: Springer, 2007.

2. Golz RJ, Grogan DP, Greene TL, et al. Distal ulnar physeal injury. J Paediatr Orthop 1991;11:318-25.
3. Evans DL, Stauber M. Irreducible epiphyseal plate fracture of the distal ulna due to interposition of the extensor carpi ulnaris tendon. Clin Orthop 1990;251:162-5.

4. Engber WD, Keene JS. Irreducible fracture separation of the distal ulnar epiphysis. J Bone Joint Surg 1985;67:1130-2.

5. Mizuta T, Benson WM, Foster BK, et al. Statistical analysis of physeal injuries. J Paediatr Orthop 1987:7:518-23.

6. Abid A, Accadbled F, Kany J, et al. Ulnar styloid fracture in children: a retrospective study of 46 cases. J Pediatr Orthop B, 2008;17: $15-19$.

7. Bley L, Seitz WH Jr. Injuries about the distal ulna in children. Hand Clin 1998;14:231-7.

8. Walsh HP, McLaren CA, Owen R. Galeazzi fractures in children. J Bone Joint Surg (Br) 1987;69:730-3.

9. Waters PM, Bae DS, Montgomery KD. Surgical management of posttraumatic distal radial growth arrest in adolescents. J Pediatr Orthop 2002;22:717-24.

10. Cannata G, De Maio F Mancini F et al. Physeal fractures of the distal radius and ulna: Iong-term prognosis. J Orthop Trauma 2003;17:172-80.

11. Yukihiro F, Makoto S, Tatsuo M, et al. A case of Galeazzi-equivalent lesion. Orthop and Traumatol 2006:55:368-71.

12. Stahl S, Freiman $S$, Volpin G. Anterior interosseous nerve palsy associated with Galleazi fracture. J Pediatr Orthop B 2000:9:45-6.

This pdf has been created automatically from the final edited text and images.

Copyright 2012 BMJ Publishing Group. All rights reserved. For permission to reuse any of this content visit http://group.bmj.com/group/rights-licensing/permissions.

BMJ Case Report Fellows may re-use this article for personal use and teaching without any further permission.

Please cite this article as follows (you will need to access the article online to obtain the date of publication)

Galanopoulos I, Fogg D, Ashwood N, Fu K. A widely displaced Galeazzi-equivalent lesion with median nerve compromise. BMJ Case Reports 2012;10.1136/bcr2012-006395, Published XXX

Become a Fellow of BMJ Case Reports today and you can:

- Submit as many cases as you like

- Enjoy fast sympathetic peer review and rapid publication of accepted articles

- Access all the published articles

Re-use any of the published material for personal use and teaching without further permission

For information on Institutional Fellowships contact consortiasales@bmjgroup.com

Visit casereports.bmj.com for more articles like this and to become a Fellow 